\title{
THE CONCEPT OF 'MERIT’ IN AUSTRALIA, CHINA AND TAIWAN
}

\section{ABSTRACT}

The article provides a description of Australian approaches to 'merit' and an overview of the other symposium articles on the application of merit in China and Taiwan.

The term 'merit' is commonly used in Australia, China and Taiwan as an important attribute of good government service, but it means different things in different countries, reflecting both different institutional arrangements and differences in culture.

Australia's current application of the merit principle is described in some detail. The principle and its application have been subject to debate throughout the last century and continue today. The debates reflect social attitudes at the time and developments in the role of government and the skills government requires, and changes in the Australian labour market. Key debates include the role of women, the treatment of ex-servicemen, the importance of graduate recruitment, equal employment opportunity, and staff perceptions of fairness and the application of merit in employment decisions.

China has a long tradition of autocracy and a long history of competitive examinations for joining government service. It faces the challenge of whether it is possible to embrace a merit principle where politics and administration are not distinguished. Merit is also applied within a culture that gives considerable emphasis to personal relations (guanxi).

Taiwan also draws on China's long experience with examinations. A key challenge now is whether it gives too much emphasis to equality and fair access to public sector employment opportunities and too little to the skills and experience different government agencies require.

These different approaches and different challenges reflect differences in the three countries relating in particular to the role of government, the relationship between politics and administration and culture.

\section{KEY WORDS}

Merit, Australia, China, Taiwan, politics and administration, culture. 
The term 'merit' is commonly used in all three countries - Australia China and Taiwan - to describe an important attribute of good government service, but its meaning and the way it is promoted and managed differ sharply between the three.

In broad terms, the attribute concerns 'neutral competence', the capability of civil servants to exercise their responsibilities efficiently and effectively, and impartially.

The differences in interpretation and practice across countries reflect both differences in institutional arrangements and differences in culture. These differences are highlighted in the articles in this symposium, drawn from papers presented at a workshop on Public Sector Human Resource Management organised by the Greater China Australia Dialogue on Public Administration, held at Sun Yat Sen University, Guangzhou in November 2013.

As the following articles do not include an analysis of Australia' approach, this overview opens with a description of Australian practice regarding what is known in Australia as the 'merit principle', and some of the debates about the principle and its application over the last century and continuing today. Like the papers on China and Taiwan, the Australian experience demonstrates that the concept of merit and its application are always subject to debate, and evolve over time.

\section{A. Application of the merit principle in Australia}

\section{(a) Current practice}

In Australia's federal system, the administrative arms of government are spread across the Commonwealth, the States and Territories and local governments. There are about 1.9 million public sector employees in total (ABS 2013), with the vast majority (around 77\%) working at the State/Territory level delivering the major public services (schools, hospitals, police, public transport); local government has a further $10 \%$ and the Commonwealth $13 \%$. Some of these work in government business enterprises which, since the reforms of the 1980s, are exempt from any central controls including with regard to merit, and generally apply private sector practices. The majority work in public sector agencies which are subject to Commonwealth or State/Territory employment legislation most commonly in the form of Public Service Acts which apply the concept of merit. (For a broad description of Australian arrangements and the impact of new public management reforms, see APSC 2003; a brief update is in APSC 2013b.)

Australian practice here is described primarily on the basis of Commonwealth legislation; State and Territory legislation which governs the vast majority of public sector employees is generally similar, particularly in defining and applying merit, though detailed rules and processes vary.

The current (Commonwealth) Public Service Act requires that engagement and promotion in the public service be based on merit with merit requiring: 
- An assessment of the relative suitability of the candidates for the duties using a competitive selection process;

- The assessment be based on the relationship between the candidates' work-related qualities and the work-related qualities genuinely required for the duties;

- The assessment focus on the relative capacity of the candidates to achieve outcomes related to the duties;

- The assessment being the primary consideration in making the decision.

This involves an internal assessment of the capabilities of candidates in relation to the requirements of the job and to the present and anticipated needs of the organisation with the vacancy to be filled.

Indeed, each agency is responsible for engagement and promotion decisions under Australia's devolved system of management while meeting these requirements. The Australian Public Service Commission (APSC) provides guidelines on good practice summarised in Table 1.

Table 1: APSC Recruitment Guidelines

(Source: APSC, 2013a)

\begin{tabular}{|l|l|}
\hline Stage 1 - Planning & $\begin{array}{l}\text { Step 1: Identify employment opportunity, } \\
\text { category and classification and whether } \\
\text { vacancy needs to be filled } \\
\text { Step 2: Decide how vacancy is likely to be } \\
\text { filled (ie engagement of new employee or } \\
\text { promotion or movement of existing } \\
\text { employee) } \\
\text { Step 3: Develop supporting documentation }\end{array}$ \\
\hline Stage 2 - Sourcing & $\begin{array}{l}\text { Step 4: Decide what notification is required } \\
\text { (ie is gazettal needed?) } \\
\text { Step 5: Decide if opportunity is to be open to } \\
\text { all eligible members in the community } \\
\text { Step 6: Notify in the gazette - additional } \\
\text { advertising optional }\end{array}$ \\
\hline Stage 3 - Assessing & $\begin{array}{l}\text { Step 7: Accept applications } \\
\text { Step 8: Assess relative suitability of } \\
\text { candidates }\end{array}$ \\
\hline Stage 4 - Selecting & $\begin{array}{l}\text { Step 9: Recommend preferred candidate on } \\
\text { basis of relative merit } \\
\text { Step 10: Delegate makes selection decision }\end{array}$ \\
\hline Stage 5 - On-boarding & Step 11: Implementation \\
\hline
\end{tabular}

Typically, agencies maintain duty statements for each position and review these before commencing action to fill a vacancy: the duties include the main responsibilities and any 
qualifications required, and preferably indicate what is expected to be achieved, linking these to the classification of the position (and its pay range).

Figure 1 provides an example of a recent advertisement for two vacancies at a reasonably senior level in the Australian Public Service (APS). It summarises what would be in the formal documentation about the duties of the position, the role of the relevant work unit and organisation and the selection criteria. In this example, a private search firm has been engaged to help the agency fill the positions with the best people that can be found, recognising the likelihood that they may currently be employed outside the APS (eg in a State government or in a non-government organisation (NGO)). 


\section{National disabilityinsurance Agency}

\section{Branch Manager, People and Culture Branch Manager, Communications and Engagement \\ (Head Office roles - SES Band I) \\ National Disability Insurance Agency (NDIA) is an independent statutory agency, whose role is to mplement the National Disabilicy Insurance Scheme. A learning organisation in start-up phase the NDIA currently has two unique opportunities to join and contribute to the foundations of the Agency, Reporting to the GM, Governance these roles are critical to achieving the Agencys mission}

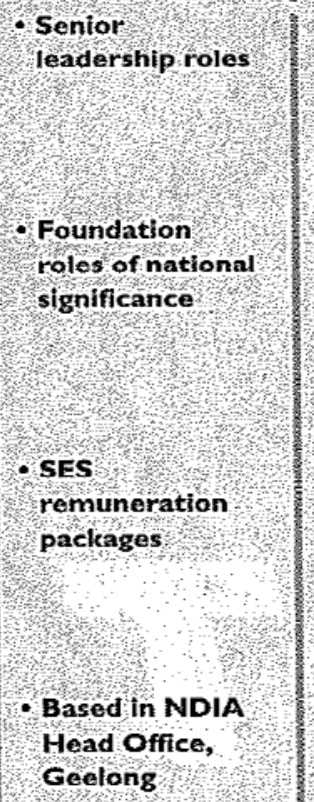

Branch Manager, People and Culture

Ref 64804

As the Branch Manager, Pcople and culture you will assist in leading the cultural and capability development of NDIA. You will work collegiately with the senior leadershíp tean actively promoting HR policy reforms and best prectice to support the cultural values of the Asency. In building a policy reforms and best practice to support the curelops implements and divo NDIA's evolving services, while adding value to each of its many stakeholders. The NDIA seek an experiencoo practitioner with demonstrated excellence in leadership, exceptional skils in workforce planning and organisacional culture and who enjoys the chialtenges of a start-up organisation. Demonstrated ability to exemplify the integricy and professionalism of the APS values must be evident

Branch Manager, Communications and Engagement Ref 64803 As the leader of NDIA's communications and engagement strategles you will proactively manaze all NDIA communications, including stakeholder engagement prograns, government relations, media, online and contribute to internal communications, You will be an exceptional leader and a strategic communications thinker and tactician also capable of continuing to butd and gevolve the identity of the agency in continuing to develop communications plans and enhance the NDIS story using modern and contemporary communications, you may also have experience as a spokesperson.

Both of these positions require high energy and resilient people with proven leadership, management skills and experience. These positions are only open to APS employees. For more information on each of these roles refer to the contace details below.

NDIA aims to attract and retain scaff with a disability and provide support and opporcunitie to its diverse team. People with disability and the roquired experience and competencies ar oncouraged to apply

More information is available by contacting Louise Glanville NDIA on 0417 o1 2475 or Christine O'Donnell, Talent Partner on (02) 90876223 . Applicants can request candidate information by emailing recruit.ausgov@talent2.com quoting the reference number for the position

Applications close at midnight on Monday 21 April 2014

\section{recrut A B L ITI (1)}

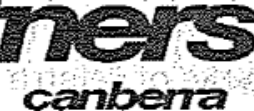

Figure 1: A recent APS job advertisement

(Source: Talent Partners 2014)

As a rule, positions are advertised not only for internal APS candidates but also for external applicants, and selection criteria are identified and made known to applicants. Vacancies are required to be advertised in the Government Gazette, and may also be advertised in the press at the instigation of the relevant agency (this is standard practice for base level vacancies and for all Senior Executive Service positions, and is very common for other vacancies). Assessments are usually made by a small panel with a balance of perspectives (eg gender balance, experience outside the relevant work unit as well as inside), who 
shortlist candidates from written applications (and sometimes written psychological or other tests or examinations, particularly in the case of bulk recruitment exercises), conduct interviews and consider referees' reports before recommending a candidate to the delegate with the authority to make a decision.

Accepted offers of employment or promotion are published in the Gazette. Engagements from outside the APS are commonly subject to a 12 month probation period. Promotions (from within the public service) require more than seniority or proven performance at the person's current level: to be successful, an internal candidate must demonstrate capability at the level and in the position concerned, and superiority over all other candidates.

Promotion decisions may be appealed by other internal candidates, each agency being required under the PS Act to have a 'fair system of review of employment decisions'. The APSC has guidelines for good practice in this, promoting 'healthy organisations' and a 'healthy culture' that ensures respectful, positive, collaborative and prompt processes of review (APSC 2012). Internal review decisions are also open to appeal to the Merit Protection Commissioner, a statutory position in the APSC, though such appeals are now few in number.

For the SES, who represent the leadership cadre of the APS comprising around the top $2 \%$ of APS employees, the process of appointment or promotion is subject to 'certification' by the APS Commissioner. In practice this involves having a representative of the Commissioner on the selection panel, the Commissioner's approval of the selection criteria, open advertising of the vacancy, and consideration by the Commissioner of the selection panel's report and a short report from the Commissioner's representative about the process and quality of the field of applicants. The final decision, however, lies with the agency head, not the APSC.

Agency head appointments are governed by a very separate process. Departmental secretaries are formally appointed for a specified term (usually five years) by the GovernorGeneral on the advice of the Prime Minister who must first receive a report from the APS Commissioner and the Secretary of the Department of Prime Minister and Cabinet. This ensures some merit consideration but the PM is not bound at all by the officials' report. Some other agency head positions are subject to similar (limited) constraints through a 'Merit and Transparency Policy' initiated in 2011, and a few (such as the Auditor-General) require consultation with the Parliament, but are not formally endorsed by the legislature as in the US.

(b) Australian debates about 'merit'

Notwithstanding over a century of experience in applying 'merit' within the APS, the application has been subject to debate throughout this experience, and continues today. Indeed, the merit principle was rarely an objective guiding principle and was continually moderated by prevailing social attitudes (Colley 2006). 
The original 1902 legislation focused on 'efficiency' which meant the 'special qualifications and aptitude for the discharge of the duties of the office to be filled together with merit and good and diligent conduct' (see APSC 2004, p71). Drawing on the 1854 Northcote Trevelyan Report (Northcote Trevelyan 1854) and subsequent British developments, appointment to the public service was by way of prescribed competitive examinations to test the 'efficiency and aptitude' of applicants. Recruits entered at the bottom of one of three divisions: the Professional Division (a small minority of recruits with needed qualifications, particularly lawyers and engineers), the Clerical Division (recruits who had completed school education) and the General Division (the majority of recruits with more limited education, many of whom developed technical skills on the job). The education examination was 'of an elementary or rudimentary character' reflecting the assumption of a lifetime career service that started at the bottom. Promotion was based on the 'relative efficiency' of candidates or, if the best candidates were considered equally efficient, then 'relative seniority' would be considered.

\section{Women}

The legislation did not exclude women, but that was certainly the practice. Women were not allowed to undertake the examination for permanent appointment, a bar which remained for many decades. The bar was relaxed (initially only to allow permanent appointment to the lowest division of jobs and then in 1949 to allow permanent appointment to clerical and professional positions), but a bar on married women having permanent positions remained in place right up until 1966 (APSC 2003). Women remained very much in the minority other than in the lowest division (which included typists, dataentry operators and clerical assistants, positions dominated by women), and were rare beyond the lower grades of the clerical division until into the 1980 s.

Concern about gender balance was expressed not only in terms of equal employment opportunities (EEO) and the rights of women, but also in terms of the merit principle: the failure to make best use of available talent. Another aspect was the need for the public service to better reflect the Australian community (a major theme of the 1976 Royal Commission into Australian Government Administration (RCAGA 1976)). In response, considerable effort has been put into ensuring fair treatment of women since the 1970s through such measures as improved training opportunities, mentoring, female representation on selection committees, improved family leave arrangements and flexible working hours, all entirely consistent with merit.

Women now have a slight majority of positions in the APS, but continue to be underrepresented amongst agency heads and the SES in particular (APSC 2013d, Table 9). Significant progress has been achieved at 'executive levels' just below the SES, and in the SES, and further progress is very likely from the existing momentum up the grades, but women's share of top positions may not stabilise as high as $50 \%$ on current trends. Whether 
this reflects a continuing lack of equal opportunities and failure to apply merit, or simply reflects the choices women make freely about careers and families, remains at issue.

Ex-servicemen's preference

The First World War led to another constraint on 'merit' that lasted for many decades: the preference given to ex-servicemen. First introduced in 1915 and extended in 1917, the veterans' preference was included in the new Public Service Act in 1922. It was extended again during World War 2, though the legislation passed in 1945 required all employers, not just the public service, to give returning servicemen preferential treatment when filling jobs. By the 1950s, it was apparent that preference for veterans was having an adverse impact on the capability of the public service, lowering average educational standards, limiting access by younger people and increasing the average age of public servants (Parker 1959, Boyer 1959).

\section{Graduate recruitment}

The strict adherence to the policy of lifetime careers also began to constrain the merit principle as demands on government increased and the benefits of recruiting university graduates began to be raised in the 1930s. The Northcote Trevelyan Report had in fact proposed a separate recruitment path for those expected to engage in 'intellectual' work focused on graduates but this idea was not pursued in Britain until after the First World War (Lowe 2011). An age bar on the Australian public service examination, and the requirement that recruitment to permanent jobs only be at the lowest level in each division, also made graduate recruitment very difficult in Australia, other than for the small number of 'professionals'.

Some relaxation of these obstacles was introduced in 1933 allowing up to $10 \%$ of vacancies in the combined clerical and professional division (by then called the 'third division') to be filled by graduates. This came only after robust debate about whether graduate recruitment would be 'elitist' given the cost of university education which meant that only wealthier families could offer such education to their children at that time. A very small number of graduates were recruited into the Commonwealth Public Service in the 1930s and early 1940s, several of whom became prominent leaders in the later 1940s and 1950s. The concern about 'elitism' was not without some foundation, however. In one State (Queensland), the public service examination was already subject to a high fee, the test was skewed to those educated in private schools and there was a low pass mark, leading to criticism that only 'young, healthy and wealthy' (and not bright) men were being recruited (Colley 2001).

There was growing recognition of the need for a better educated 'administrative cadre' that was not recruited directly from school into the bottom grades, but recruited and developed to take on more professional and leadership roles (Parker 1942). Serious action on this, 
however, only took place two decades later after a major inquiry (Boyer 1959). The Public Service Board introduced a general graduate recruitment program in 1961 and established from this an elite 'administrative trainee' program from 1963. The Commonwealth Bureau of Census and Statistics and the Treasury also established cadetship schemes in the 1960s aimed to recruit top economics, statistics and mathematics undergraduates while still at university. Nonetheless, graduate recruitment and the career development of professional analysts and policy advisers affected only a small minority of the public service until the 1980 s, though it did have a major impact on policy and management capacity. Subsequently technological change, commercialisation of government businesses and increased educational standards in the community led to massive reductions in positions for unskilled and narrowly skilled technical staff (leading to removal of the former dominant 'general' or 'fourth' division), and a shift towards a graduate public sector workforce (APSC 2013c).

Equal employment opportunities (EEO)

Another major development in the 1960s and 1970s affecting the way 'merit' was interpreted came with EEO and 'affirmative action'. The first stage was largely uncontroversial involving the removal of direct obstacles to women's employment. Subsequently and with considerable debate positive measures were introduced to improve access by several groups (particularly women, Aboriginal and Torres Strait Islander people, people from non-English speaking backgrounds and people with a disability) who were perceived to be discriminated against and who did not have equal employment opportunities (Stanton 1978).

The EEO agenda remains a priority, particularly for disadvantaged groups other than women, in part because of the lack of success of measures taken so far. Indigenous employment rose until the mid-2000s but has declined a little since (APSC 2013c, page 97), perhaps because of the sharp reduction in lower level positions and the emphasis on graduate employment. Effort is currently being directed towards finding new pathways into the APS. Employment of people with disabilities has continued to decline now for over a decade (APSC 2013c, page 97). The cause is unclear but may include the emphasis these days on people having multiple skills, limiting the number of jobs that can be designed for people with more limited skill sets.

More recent developments and issues

In several respects, the emphasis on 'merit' has increased in recent decades (Nethercote 1996). The term was first defined in the Public Service Act in 1984 and accompanied by the Merit Protection (Australian Government Employees) Act 1984 which established the Merit Protection Review Agency, giving more prominence to a role previously exercised by the Public Service Board. The MPRA was later subsumed into the Public Service and Merit Protection Commission (later the Australian Public Service Commission) but with a dedicated statutory officer (the Merit Protection Commissioner (MPC)). 'Merit' was defined 
and applied more comprehensively in the 1999 Public Service Act which also prohibited ministers from giving directions regarding employment decisions within the public service.

The opening up of the APS in the 1980s and 1990s, with greater mobility within and beyond the APS, widened competition for positions and hence effectively gave more weight to the application of the merit principle. Previous practice under which most above-base positions were advertised for internal candidates only was replaced with an expectation that vacancies were open to candidates outside the APS as well as those inside. All SES positions are required to be open to outside candidates, and indeed to be widely advertised, and many others are also advertised in the press. Lateral engagement is far more common than in the past.

Despite this evidence of a strengthening of the application of merit in Australia, there remain issues requiring careful attention.

First, the increasing emphasis on the suitability of candidates for particular jobs and for present and future needs of organisations (or the APS as a whole), has led to renewed interest in career management and succession planning etc. This requires some balancing to ensure those identified as having potential for senior positions (and hence deserving of extra investment in training and development) are not given unfair advantage over other candidates when the vacancies occur. Whether and how merit should be applied in decisions on short-term vacancies (while the occupant is on leave for example) have also been debated in recent years: some employees argue that formal merit selection is always required for fairness, some managers and staff argue that a simple rule such as seniority amongst those at the next level in that work unit avoids unnecessary administrative effort in such cases while avoiding most complaints of unfairness, and some managers argue that emphasis should be given to use such vacancies explicitly for development purposes as part of 'career management' without any formal merit-based selection.

The current Merit Protection Commissioner has emphasised the need to balance the process requirements to ensure application of the merit principle against the importance of timely decisions and cost-efficient management of recruitment (Godwin 2012). On the other hand, when surveyed, a significant proportion of non-SES staff did not agree that their agency 'routinely applies merit in decisions regarding engagement and promotion': in fact, only $40 \%$ agreed their agency did.

\section{Table 2: Views of Australian non-SES about the application of merit}

(Source: 2012 APSC Staff Census, accessed at www.data.gov.au)

My agency 'routinely applies merit in decisions regarding engagement and promotion':

\begin{tabular}{|l|c|c|}
\hline & $\%$ & $\%$ \\
\hline Agree strongly & 5.4 & \\
\hline
\end{tabular}




\begin{tabular}{|l|c|c|}
\hline \multicolumn{1}{|l|}{ Agree } & 34.1 & \\
\hline TOTAL AGREE & & 39.5 \\
\hline Disagree & 16.4 & \\
\hline Disagree Strongly & 8.4 & 24.8 \\
\hline TOTAL DISAGREE & & 31.2 \\
\hline Neutral & & 4.5 \\
\hline No response & & 100.0 \\
\hline \multicolumn{1}{|c|}{ TOTAL } & & \\
\hline
\end{tabular}

Note: 87,209 staff participated in the census

Some of those who do not agree that merit is being applied may, as the MPC seems to suggest, misunderstand the need for balancing merit considerations and the need for timely decisions and efficient processes, and some may be disappointed about not winning a recent promotion (not surprisingly, an APSC study (APSC 2006, page 71) suggests such people are twice as likely to report merit not applying as those who are successful). Nonetheless, a quarter of all staff reporting they believe merit is not routinely applied should be of concern.

Australian approaches for top appointments have also been subject to criticism (eg MacDermott 2008; Podger 2007) and, despite action to address some of these concerns, the termination of several departmental secretaries by various Prime Ministers in recent years has re-opened concern about politicisation at the top of the APS. Similar concerns are frequently raised about top appointments in State Governments (eg Podger 2005).

The failure to include merit amongst the simplified list of APS Values in the 2013 amendments to the Public Service Act (although it remains as one of the 'employment principles') has also attracted criticism (Podger 2013) given the centrality of the merit principle in the Northcote Trevelyan Report that shaped much of Australia's public service arrangements since the turn of the twentieth century.

\section{B. Chinese practice}

It is difficult to describe the size and composition of the Chinese public sector in terms that bear a resemblance to western concepts and typologies. State-owned enterprises (SOEs) continue to play a huge role in China. While reforms have been leading them towards more competitive arrangements and more private-sector style employment practices, the boundaries between public and private, and between commercial and non-commercial within the public sector, are still blurred. The lack of a distinction between politics and administration also makes it difficult to measure the size of China's 'civil service' in a way that is directly comparable to Australian measures. Some effort is now being directed to the governance of what is termed 'public service institutions' (such as schools, hospitals, universities), but it is still not possible to clearly define and measure employment in these as distinct from what might be considered in Australia as the 'core' civil service. Very broadly 
(essentially no more than a 'guesstimate'), of a total workforce approaching 800 million, there would seem to be around 70 million working in SOEs and another 200 million or so working in public service institutions (derived to the extent possible from the China Statistical Yearbook 2013). There is a 'cadre workforce' within this public sector of about 7 million, the great majority of whom work at the grass-roots level; only about 2,500 nationwide form ministry-level officials (or most clearly political leaders).

China has a strong tradition of autocracy and a long history of competitive examinations for joining the government service. Chinese leaders take pride in the establishment of a monolithic but unified one-party-led political system. On the face of it, in many respects the communist regime fares well with its tradition of autocracy. But without building up a service system that can deliver, and meet citizens' expectations, can an autocratic, oneparty led policy withstand all of today's global challenges?

A related question raised is whether, given the high degree of unification of politics and administration, it is possible to embrace a merit principle in personnel management in China. An easy answer is that no government in the world can conceivably deny some form of merit principle in daily administration. Leaving aside that understanding, the article by Lijun Chen, Hon Chan, Jie Gao and Jianxing Yu in this issue of AJPA clearly show that political patronage or loyalty has taken the centre stage since the establishment of the People's Republic of China in 1949, alongside the real need to adopt a merit principle in China's personnel management system. Chen et al also reveal, however, how much the balance has been shifting towards merit since China's opening up from 1978.

Perhaps more than Australia's performance management arrangements, the cadre personnel management system in China sets a range of performance targets for individuals and organisations and uses this for promotion purposes. Many are mission-based including economic targets (for example, the total amount of industrial output; per capita annual net income of peasants) and public service targets (the percentage of rural residents vaccinated against infectious diseases). The system also sets non-mission-based targets some of which would be regarded as 'political' in Australia. There are mainly three types of such targets in place: (1) anti-corruption targets (eg ensuring that spending on such items as meals and entertainment are less than the amount spent in the previous year), (2) social development targets (eg implementing family planning policies, limiting the number of mass petitions to the Central Government), and (3) explicit political targets (eg conducting ideological indoctrination through regular study sessions) (Chan and Gao, 2013). The proliferation of performance targets in China provides strong evidence of the recognition of embracing a merit principle in personnel management in today's China, albeit very different from the Australian approach.

The extremely small number of ministry level officials - mayors, provincial leaders, national leaders - suggests the likelihood that the people concerned are highly competitively selected and have worked their way up in the hierarchy. Confidence in their 'performance' 
must have been established in their early careers. Like their counterparts in Australia, political credentials are important for advancement to this level of position on top of good job performance.

Hence, an important aspect to understand is the essential function of the 'nomenklatura' system in cadre personnel management in China. This system closely monitors the selection, recruitment, appointment, removal, appraisal and transfer of 'core' cadres at each level of government. To a certain extent, political credentials are vital to those officials at or above ministry-level in the State Council or those holding leading positions in respective local governments for upward career mobility. In general, appointment and placement of core cadres at each level of government is susceptible to political interference and partisan patronage. Yet, in daily administration, the merit principle is still featured in China broadly as elsewhere in the world.

The opening up of the Chinese market to the world since 1978 has presented Chinese leaders with a problem of capacity deficit in its cadre personnel management system. Because the traditional nomenklatura system was not designed in a way to nurture talent to meet the challenges posed by the opening up of the Chinese market, Chinese leaders have needed to find a way to develop an additional HRM mechanism to manage talent.

Chen et al discuss the general background that led to the National Recruitment Program of Global Experts. The program clearly gives expression to the need for adopting a merit principle that will nurture the talents required for leading China to be more competitive in the market, both within and outside China, as well as in the delivery of public services. The program requires governments from the Central to the County levels to map out specific plans to drive, motivate, and encourage talent to develop private businesses and enterprises and establish scientific research centres. 'Local organization departments' coordinate with local agencies, whatever their core functions, to implement the plans, set up local leading groups and talent work offices and seek funding to support related activities. This is a breakthrough because giving funding to organization departments at all levels to carry out such national and local programs is a departure from standard HRM practices in the past in China. Political credentials are no longer the main currency to recruit the experts enrolled under the National Recruitment Program of Global Experts and other similar programs developed locally.

In his article in this issue, Zhibin Zhang also highlights the increased emphasis on merit since China's opening up drawing particular attention to Deng Xiaoping's 1980 appeal to 'four transformations' of the cadre workforce including being better educated and professionally more competent. He remains concerned, however, about two remaining non-meritocratic features: the lack of a concept of political neutrality and the way incumbent civil servants exercise authority as if their views represent party policies or decisions. Zhang explores bureaucratic and familial cultures in China and uses a series of case studies to illustrate how in practice these have constrained the capacity of reformed institutional arrangements to 
adopt meritocracy, by allowing partisan influences and personal loyalties to affect HRM arrangements.

Liang Ma, Huangfeng Tang and Bo Yan in their article make the case that both a merit principle and guanxi (i.e. patronage relationship) are instrumental to career mobility of civil servants in China. Using a survey of nearly 900 civil servants, they analyse perceptions of what determines promotions. Their finding is not only that both performance and guanxi play a role but that those perceiving this 'ambidextrous' influence are the ones most satisfied with promotional fairness. Accordingly, the finding is not presented as necessarily a matter for great concern so long as the Chinese authorities keep the extent of nepotism in the civil service under control to better safeguard its integrity.

\section{Taiwanese practice}

According to official statistics released by the Ministry of Civil Service (MOCS) (http://www.mocs.gov.tw/pages/detail.aspx? Node=1123\&Page=4350\&Index=4, visited on January $20,2015)$, by the end of September 2014, there were 344,029 civil servants in Taiwan, with $54.09 \%$ employed by the central government and the remaining $45.91 \%$ by the local governments. Among them, 230,977 persons (67.14\%) were serving in administrative offices, 66,196 (19.24\%) in public enterprise, 20,024 (5.82\%) in hygiene and medical service, $26,832(7.80 \%)$ as public school staff. The total of 344,029 in 2014 compares to a peak of 442,972 in 1996 . The $22 \%$ reduction, coupled with a constantly rising demand for government services, suggests not just an increase in efficiency but also that the Taiwanese civil service sector may have to increase its capacity by bringing in more talented people and applying the merit principle more effectively in its personnel management processes. (MOCS data refer only to civil servants who pass the formal civil service examinations and do not include large numbers of public employees on contracts, but the Directorate-General Personnel Administration does not publish its data on all public employees.)

Taiwanese arrangements are described in some detail article by Bennis So in this AJPA symposium. Engagements and promotions to certain key levels in the civil service are decided upon through the independent Examination Yuan, an executive agency but functionally separate from the operational agencies with positions to be filled. Agencies cannot fill these positions other than by candidates who successfully pass the relevant examination, though they may have some influence over which successful candidates they are allocated. Positions above certain levels can only be filled by internal public service candidates. Promotion or appointment is not based upon having a particular vacancy to fill: while agencies can influence the recruits they receive, people are appointed or promoted to a 'level' and agencies are allocated successful candidates.

Between the key levels subject to the Examination Yuan process, agencies may promote staff (but not engage people from outside), generally doing so on the basis of experience, performance and seniority. 
The Examination Yuan process applies across government, including local government, and the examinations are managed centrally. This process reflects the numbers of applicants for government jobs, as well as the long history of examinations.

So argues that the Taiwanese approach runs the risk of excessive emphasis on generic skills with insufficient regard for the skills and experience required by different agencies or the mix of staff they require. It may also fail to meet the wishes of candidates, and involve excessive delays in filling positions. On the other hand, the process is clearly independent and offers an even playing field in the context of very large numbers of applicants for few positions. In effect, So demonstrates that 'hiring by examination' in today's Taiwan civil service reveals that central to the merit principle in Taiwan is the value of 'equality' (in terms of the public's access to public sector employment opportunities), not 'competence'.

\section{Discussion and Conclusion}

It is very clear from this symposium that 'merit' can have different meanings in different contexts, and is constantly subject to debate in each context. The main contextual factors appear to be the institutional arrangements in each country (both the role of government in the society and the relationship between politics and administration) and cultural factors.

(a) The role of government

In Australia, the role of government in the market economy has meant 'merit' is generally only considered an attribute to be regulated in the context of the public sector, and then only for non-commercial activities. Government certainly invests heavily in education and human capital more generally, but leaves to the market how that capital should be deployed. The exceptions are limited, through for example anti-discrimination law and accreditation requirements for public safety.

For China, Chen et al note that the transition towards a market economy and the demands to improve competitiveness and thereby increase living standards has included not only enormous investments into education but also other measures to promote expertise and the application of a more merit-based approach to HRM across all sectors. Merit is being promoted not only within the public sector but also across the emerging private sector and certainly amongst SOEs.

\section{(b) Politics and administration}

Central to understanding the different approaches to 'merit' are the institutional differences regarding politics and administration.

The 'merit principle' in Australia is fundamentally associated with a distinction between politics and administration. Derived from British reforms in the mid-nineteenth century (Northcote Trevelyan, 1854), this distinction was aimed to stop political patronage and nepotism and to promote efficiency, requiring appointments to the civil service to be based 
on objective testing of skills and knowledge and for advancement within the service to be similarly based on assessments of experience and performance. The First Annual Report of the Public Service Commissioner in 1904 noted that the Commonwealth Public Service Act had the

'manifest intention ... that all appointments and promotions should be based upon a just and equitable system excluding all political and other patronage, throwing all appointments open to rich and poor alike, and establishing merit combined with fitness as the only basis of selection' (quoted in Stanton 1978, page $5)$.

The principle is linked closely to concepts of impartiality of administrative decision-making within the policy frameworks determined by the political arm of executive government. Such concepts of impartiality and proper administrative decision-making have been reinforced in recent decades by administrative law further constraining political influence. In the case of public service employment decisions, the merit principle in the legislation is now complemented by a specific provision that prohibits direction by politicians, and a core value of the public service is its non-partisanship (or being 'apolitical' to use the term in the current Public Service Act).

China's long history of competitive examinations for entry into government service has never been based on the separation of politics and administration. The Chinese concept of 'merit' is related more to a competition for access to power and influence (and the rewards associated with these), and to ensuring high authority has support from the most able of its citizens, the examinations being based on education and knowledge of philosophy, and advancement based on loyalty as well as achievement. This approach has remained following the Communist Party of China coming to power in 1949. While a distinction between politics and administration was debated briefly in the 1980s, it has since been firmly rejected with the Constitution giving the CPC the central role over all arms of government.

Chen et al and Zhang show how nonetheless merit in terms of competence and performance has been given increasing emphasis since China's opening up under Deng Xiaoping. Political loyalty is still required, particularly amongst the cadre workforce, but merit increasingly dominates. Indeed, as the Government explores options regarding the future governance of public service institutions, some de facto distinction between politics and administration may evolve with merit determining most appointments and promotions.

China's determination not to formally distinguish between politics and administration makes understanding of its concept of 'merit' and its approach to applying 'merit' critical. The combination of, and balance between, administrative competencies and political skills (including loyalty to the $\mathrm{CPC}$ ), and how these different factors are assessed, are clearly shifting, and warrant careful and continuing study. 
Taiwan shares China's long history of the use of examinations to test 'merit' but has also, through the democratic reforms in the 1980s and 1990s, begun to establish a distinction between politics and administration within the executive arm of government. As Bennis So explains, the examination system continues to dominate the whole process of recruitment and advancement within the civil service, not articulating a 'merit principle' per se that constrains political influence, but the system in practice enforcing highly centralised decisions independent even of the agencies (and the agencies' political leaders) where the civil servants will work.

Political advancement in Australia, as in other democracies (including Taiwan), has its own rules and processes which in a broad sense involve considerations of 'merit'. In the final analysis, the electorate makes its assessment in each election of the relative merits of the candidates and their parties, including whether the policies espoused are those the public prefers and whether they have the competence to deliver those policies. Successful politicians must generally demonstrate, both within their parties and in their own actions, skills in communication, advocacy and networking along with other skills and experience such as in policy development and in business or community acumen. Some aspects of these attributes that are valued in politics may be relevant to senior public servants (such as political acumen and communication skills) but others directly conflict with the concept of merit within the civil service, for example partisan loyalty and personal obligations to individuals and networks.

\section{(c) 'Merit' and culture}

The concept of merit may also vary with differences in the culture of the community in which the government operates. The Australian approach, like that of many other Western nations, reflects the 'rule of law' based upon impartiality whereas Chinese Confucianism is often described as the 'rule of morality' (Yang and Van der Wal, 2014; Minzheng and Xinhui, 2014; Podger and Menzel, 2014). The latter emphasises the 'virtues' of good leaders, and reflects values such as filial piety and respect for authority (so long as it exhibits moral behaviour) with an emphasis on personal relationships (or guangxi).

Liang Ma et al canvass directly the respective roles of guangxi and merit in promotions within the Chinese Government (or at least the Party cadres within the Government). They identify a mixture of the two and, interestingly for Australian readers, conclude that 'In a guangxi-oriented society, you cannot expect to be entirely insulated from its influence, but rather to keep its erosion of civil service integrity under control'.

Zhang seems less comfortable, drawing attention to bureaucratic as well as social cultures and the risks of nepotism and other integrity failures.

Australia's own history demonstrates how 'merit' has been affected by contemporary social values. Unease amongst civil servants themselves about the current application of merit 
suggests there remain concerns about bureaucratic cultures, or at least rather significant differences of opinion of what merit should mean in practice.

\section{Conclusion}

It is apparent that there is no universal definition of merit, nor a single ideal approach to its application. It is nonetheless a central public service value in every jurisdiction, and worthy of continuing research and debate. 


\section{REFERENCES}

Australian Bureau of Statistics, 2013, Employment and Earnings, Public Sector, Australia, 2012-13, (ABS 6248.0.55.002), accessed at www.abs.gov.au

Australian Public Service Commission (APSC) 2003, The Australian Experience of Public Sector Reform, APSC Occasional Paper 2, Canberra

APSC 2004, A History in Three Acts: Evolution of the Public Service Act 1999, APSC Occasional Paper 3 (by Bob Minns), Canberra

APSC 2006, State of the Service Report 2005-06, November, Canberra

APSC 2012, Not just about process: the review of actions scheme, (A human resources practitioner's guide to responding to and managing employee complaints and disputes), Office of the Merit Protection Commissioner, Canberra

APSC 2012, 2012 APSC Staff Survey, accessed at www.data.gov.au APSC 2013a, APS recruitment guidelines - operational guidance for agencies, Canberra APSC 2013b, 'Background Paper on Australian Public Sector', Staff Research Insights, by Kathy Potts, Canberra

APSC 2013c, State of the Service Report 2012-13, Canberra

APSC 2013d, APS Statistical Bulletin 2012-13, Canberra

Boyer, Sir Richard, 1959, Report of the (Boyer) Committee of Inquiry into Commonwealth Public Service Recruitment, Government Printer, Canberra

Chan, H. S. and Gao, J., 2013, 'Can the Same Key Open Different Locks? Administrative Values Underlying Performance Management in China', Public Administration Review, 91(2): 366-380

Colley, L., 2001, 'The Changing Face of Public Sector Employment', Australian Journal of Public Administration, 60(1): 9-20

Colley, L., 2006, 'Approaches to the Merit Principle in Queensland Public Service Recruitment 1859-2000. From rich and dumb to gender discrimination to politicisation', Australian Journal of Public Administration, 65(1): 46-60

Godwin, A., 2011, 'Merit and its merits: Are we confusing the baby with the bathwater?' Australian Journal of Public Administration, 70(3): 318-326

Lowe, R., 2011, The Official History of the British Civil Service: Reforming the Civil Service, Volume 1: The Fulton Years, 1966-81, Routledge, Oxford 
MacDermott, K., 2008, Whatever Happened to Frank and Fearless: the impact of new public management on the Australian Public Service, ANU Press, Canberra

MingZheng, X. and Xinhui, W., 2014, 'Chinese Leadership: Culture and Confucianism', Public Integrity, 16(2): 165-172

National Bureau of Statistics of China, 2013, China Statistical Yearbook 2013, Beijing, China Statistics Press

Nethercote, J., 1996, 'The Australian Public Service as a Career Service: Past, Present and Future', in Weller, P. and Davis, G. (eds), New Ideas, Better Government, Allen and Unwin, St Leonards NSW

Northcote, S. H. and Trevelyan, C. E., 1854, Report on the Organisation of the Permanent Civil Service, House of Commons, London

Parker, R. S., 1942, Public Service Recruitment in Australia, Melbourne University Press, Melbourne

Parker, R. S., 1959, 'Recruitment - Aims, Methods and Problems Emerging', Australian Journal of Public Administration

Podger, A., 2005, 'Some Contemporary Challenges for Efficient, Effective, Equitable and Ethical Public Services', address to IPAA National Conference, November

Podger, A., 2007, 'What Really Happens: Departmental Secretary Appointments, Contracts and Performance Pay in the Australian Public Service', Australian Journal of Public Administration 66(2): 131-147

Podger, A., 2013, 'Mostly Welcome, but are the Politicians Aware of What They have Done? The Public Service Amendment Act 2013', Australian Journal of Public Administration 72(2): 77-81

Podger, A. and Menzel, D., 2014, 'East-West Values and Ethical Leadership in China', Symposium Introduction, Public Integrity, 16(2): 159-164

Royal Commission into Australian Government Administration (RCAGA), 1976, Final Report, Volume 1, (Also known as Coombs Report), AGPS, Canberra

Stanton, M. A., 1978, The Merit Principle: Its History and Future, Public Service Board Research Paper 1, AGPS, Canberra

Talent Partners, 2014, 'National disabilityinsurance Agency: Branch Manager, People and Culture; Branch Manager, Communications and Engagement' (advertisement), 12 April, p14

Yang, L. and van der Wal, Z., 2014, 'Rule of Morality vs, Rule of Law? An Exploratory Study of Civil Servant Values in China and the Netherlands', Public Integrity, 16(2): 187-207 
